\title{
Acute Myeloid Leukemia with t(8;21); (q22; q22.1); RUNX1-RUNX1T1
}

National Cancer Institute

\section{Source}

National Cancer Institute. Acute Myeloid Leukemia with t(8;21): (q22; q22.1); RUNX1-

RUNX1T1. NCI Thesaurus. Code C9288.

An acute myeloid leukemia with $\mathrm{t}(8 ; 21)(\mathrm{q} 22 ; \mathrm{q} 22.1)$ giving rise to RUNX1/RUNX1T1 fusion transcript and showing maturation in the neutrophil lineage. The bone marrow and the peripheral blood show large myeloblasts with abundant basophilic cytoplasm, often containing azurophilic granules. This type of AML is associated with good response to chemotherapy and high complete remission rate. 